\title{
Effect of forming gas annealing on the degradation properties of Ge- based MOS stacks
}

F. L. Aguirre ${ }^{a, 1,2}$, S. M. Pazos ${ }^{a, 1,2}$, F. R. Palumbo ${ }^{a, 1,2}$, S. Fadidab, R. Winterb, M. Eizenbergb

a National Scientic and Technical Research Council (CONICET), Godoy Cruz 2290, Buenos Aires, Argentina

${ }^{1}$ GAIANN, Comisión Nacional de Energía Atómica, Gral. Paz 1499 (1650), San Martín, Provincia de Buenos Aires, Argentina.

${ }^{2}$ Departamento de Ingeniería Electrónica, Facultad Regional Buenos Aires, Universidad Tecnológica Nacional, Medrano 951 (C1179AAQ), Buenos Aires, Argentina. ${ }^{b}$ Department of Materials Science and Engineering, Technion-Israel Institute of Technology,32000 Haifa, Israel.

\section{Abstract}

The influence of forming gas annealing on the degradation at constant stress voltage of multilayered germanium-based Metal-Oxide-Semiconductor capacitors ( $\mathrm{p}-\mathrm{Ge} / \mathrm{GeO}_{x} / \mathrm{Al}_{2} \mathrm{O}_{3} / \mathrm{High}-\mathrm{K} / \mathrm{Metal}$ Gate) has been analyzed in terms of the $\mathrm{C}-\mathrm{V}$ hysteresis and flat band voltage as function of both negative and positive stress fields. Significant differences were found for the case of negative voltage stress between the annealed and non-annealed samples, independently of the stressing time. It was found that the hole trapping effect decreases in the case of the forming gas annealed samples, indicating strong passivation of defects with energies close to the valence band existing in the oxidesemiconductor interface during the forming gas annealing. Finally, a comparison between the degradation dynamics of Germanium and III-V (n-InGaAs) MOS stacks is presented to summarize the main challenges in the integration of reliable Ge - III-V hybrid devices.

\section{Introduction}

As the physical dimensions of transistors scale down, the velocity saturation of carriers in the MOSFET channel (mainly caused by optical phonon emission[1]) has become a limiting factor in 
This manuscript was accepted by J. Appl. Phys. Click here to see the version of record.

Publishipegformance[2]-[4]. Inducing strain in the Si channel has been the approach to overcome this issue and enhance mobility in current Si-based CMOS processes, as it alters the band structure of the channel, increasing the occupancy of the low effective mass valley and then the mobility [5].But it has been a shortterm solution [3]. For keeping the pace of increase in the number of devices per chip, a paradigm shift is required, which considers the emergence of new channel materials, as it is defined in the International Technology Roadmap of Semiconductors (ITRS) goals [6].

Aiming to fulfill this requirement, materials with high-carrier-mobility and therefore improved injection velocity such as Germanium (Ge) - up to 4 times larger bulk mobility for holes respect to Silicon [7] - and III-V compounds (such as InGaAs) -up to 2 times larger bulk mobility for electrons have been proposed as possible candidates to replace Silicon as channel material[3], a key step in the development of high-performance P and N MOS transistors, respectively[3], [8]. Furthermore, dense 2D integration of InGaAs and Ge has been recently shown on a Si substrate[9] (Ge - III-V Hybrid Technology), utilizing standard CMOS processes. InGaAs nFETs and SiGe pFETs have been reported down to $25 \mathrm{~nm}$ spacing, along with inverters and dense SRAM cells implemented with finFETs. This novel and scalable CMOS integration scheme enables InGaAs nFET fabrication in close proximity to Ge-pFETs. In this context, it is relevant to understand the limiting factors of the Ge- and InGaAs-based MOS stacks, given the various types of defects that degrade their performance and seriously impact their reliability[10]-[12]. Therefore, the implementation of new materials in actual devices requires the capability of predicting and minimizing the long-term degradation as well as the impact of process changes on the degradation phenomena.

Regarding InGaAs, much progress has been made in the passivation of charge trapping defects in the $\mathrm{Al}_{2} \mathrm{O}_{3} / \mathrm{InGaAs}$ gate stacks, including traps at the oxide/III-V interface[13]-[16]. Nevertheless, it has been shown[17], [18] that despite of the improvement in the interface quality in terms of the passivation of both border traps (BT) and interface states $\left(D_{i t}\right)[16]$ (by suppression of Ga-O bonds), surface treatment with $\mathrm{NH}_{4} \mathrm{OH}$ and Forming Gas Annealing (FGA) $\left(\mathrm{H}_{2} / \mathrm{N}_{2}\right)$ contribute to the generation of charge in the dielectric layer by dissociation (i.e., depassivation) of the bonds at the interface[17] when a stressing voltage is applied. This causes a significant increase of the degradation rate measured by $\mathrm{C}-\mathrm{V}$ hysteresis.

On the other hand, the possibility of integrating high-k(HK) gate dielectrics on Ge substrates has been demonstrated[5], [19]leading to numerous efforts to passivate the interface defects in high-k/Ge MOS structures [19]-[22]. In particular, it has been reported a reduction of $D_{\text {it }}$ in (100) Ge MOS capacitors[21] with Post-metal-gate FGA $\left(\mathrm{H}_{2} / \mathrm{N}_{2}\right)$ of the atomic layer deposited (ALD)-HfO $\mathrm{H}_{2}$ and ALD$\mathrm{Al}_{2} \mathrm{O}_{3}[10]$, [21], [23]. 
However, despite the extensive literature available about the good interface passivation and excellent device performance obtained with this approach, very few reliability studies of this Ge-based MOS stack have been reported in connection with the interface passivation method by forming gas annealing (FGA). Although NBTI robustness has been shown for $\mathrm{SiO}_{2}$ passivated Ge-devices[24]-[26], it is clear that more information is needed to describe and model the mechanisms responsible for the degradation of high-k dielectric/Ge stacks.

Among the high-k dielectrics considered for these $\mathrm{Ge} \mathrm{MOS}, \mathrm{HfO}_{2}$ emerges as an attractive candidate as it has already proven its quality when paired with $\mathrm{Si}$ MOS. Nevertheless, $\mathrm{HfO}_{2}$ was found to be unstable on $\mathrm{GeO}_{2}$ [27]. On the other hand, $\mathrm{Al}_{2} \mathrm{O}_{3}$ forms a very good interface with $\mathrm{GeO}_{2}$ [28] but has a relatively low dielectric constant that hardly defines it as a high-k dielectric. A multilayer gate stack (high$\mathrm{k} / \mathrm{Al}_{2} \mathrm{O}_{3} / \mathrm{GeO}_{2} / \mathrm{Ge}$ ) is then usually propose in the literature, where the high- $\mathrm{k}$ is $\mathrm{HfO}_{2}$. However, a drawback of this multilayer integration is that the addition of materials with a relatively low dielectric constant, lowers the effective dielectric constant of the entire stack. Therefore, $\mathrm{HfO}_{2}$ has been alloyed with other metal oxides to obtain a ternary metal oxide with improved properties.

In this work, the influence of FGA on the degradation of multi-layered $\mathrm{p}-\mathrm{Ge} / \mathrm{GeO}_{\mathrm{x}} / \mathrm{Al}_{2} \mathrm{O}_{3} / \mathrm{HK} / \mathrm{MG}$ (MG stands for Metal Gate) stacks, is studied by the dynamics of the flat band voltage $\left(\mathrm{V}_{\mathrm{FB}}\right)$ and $\mathrm{C}-\mathrm{V}$ hysteresis $\left(\mathrm{V}_{\text {hys }}\right)$ under different polarities of the stressing voltage. Different High-K materials $\left(\mathrm{HfAlO}_{\mathrm{x}}\right.$, $\mathrm{HfGdO}_{x}$ and $\mathrm{HfO}_{2}$ ) are considered to analyze the effects of FGA on interface defect passivation, regardless of the HK layer employed.

\section{Experimental}

The experiments were performed on $300 \mathrm{~mm}$ p-type $\mathrm{Ge}$ - on - Si wafers where $1 \mu \mathrm{m}$ of un-dopped Ge was grown epitaxially on top of the Si substrate. Afterwards, the wafers were cleaned for $30 \mathrm{~s}$ in a diluted HF solution ( 2 wt.\%) to remove most of the native oxide. After the HF dip, the Ge surface was reoxidized in a controlled manner to obtain a $\mathrm{GeO}_{2}$ layer of $\approx 0.7 \mathrm{~nm}$ [28], [29]. Re-oxidation was done during the $\mathrm{ALD}$ of $\approx 2 \mathrm{~nm} \mathrm{Al}_{2} \mathrm{O}_{3}$ by means of the trimethylaluminum (TMA)/O $\mathrm{O}_{3}$ process. $\mathrm{GeO}_{x}$ (Germanium in oxidation states lower than +4) formation during this ALD process has been described before[30], [31], resulting in a $\mathrm{Ge} / \mathrm{GeO}_{x} / \mathrm{GeO}_{2} / \mathrm{Al}_{2} \mathrm{O}_{3}$ stack. On top of the $\mathrm{GeO}_{\times} / \mathrm{GeO}_{2} / \mathrm{Al}_{2} \mathrm{O}_{3}$ stack, which acts as Interfacial Layer (IL), approximately $4 \mathrm{~nm}$ of a Hf-based high-k dielectric was deposited. Such high-k layers consisted of $\mathrm{HfO}_{2}, \mathrm{HfAlO}_{x}$, and $\mathrm{HfGdO}_{x}$ and were all deposited by ALD. The Hf:M atomic ratio is 1:1. The ALD was performed at $300{ }^{\circ} \mathrm{C}$ in a cross-flow ASM Pulsar 3000 reactor, attached to a Polygon 8300 platform. The precursors used in the ALD process were: $\mathrm{HfCl}_{4}$ and $\mathrm{H}_{2} \mathrm{O}$ for $\mathrm{HfO}_{2}$ deposition and TMA and $\mathrm{Gd}(\mathrm{PPCP})_{3}$ 
This manuscript was accepted by J. Appl. Phys. Click here to see the version of record.

Publishiwgog bined with $\mathrm{HfCl}_{4}$ and $\mathrm{H}_{2} \mathrm{O}$ for $\mathrm{HfAlO}_{x}$ and $\mathrm{HfGdO}_{x}$ deposition, respectively. The notation $\mathrm{HfMO}_{x}$ will be used from now on to refer to these Hf-based high-k dielectrics. Pt (40 nm) was used as the gate electrode. Part of the samples underwent a postdeposition forming gas anneal (FGA samples) for $30 \mathrm{~min}$ at $400{ }^{\circ} \mathrm{C}$ in a gas-flow furnace using a forming gas $\left(90 \% \mathrm{~N}_{2}+10 \% \mathrm{H}_{2}\right)$ ambient, while the rest remained as control samples (no-FGA samples). These annealing conditions were chosen after comparing the results with those obtained with vacuum annealing $\left(10^{-7} \mathrm{Torr}, 30 \mathrm{~min}\right.$ in $\left.400{ }^{\circ} \mathrm{C}\right)$ and they were found to be significantly better. Summarizing, multi-layered stacks under study are approximately $7 \mathrm{~nm}$ thick, with a Pt metal gate of $40 \mathrm{~nm}$. Further details about the fabrication process can be found in our previous papers [28], [29], [32].

Capacitance - Voltage (C-V) measurements were carried out using an Agilent 4285A LCR meter. Current-Voltage (I-V) and Constant-Voltage-Stress (CVS) measurements were performed using a Keithley 2636B Source Measurement Unit. During CVS, the stress was periodically interrupted for C-V measurements to track the degradation of the device parameters such as $\mathrm{V}_{\mathrm{FB}}$ and $\mathrm{C}-\mathrm{V}$ hysteresis at $\mathrm{V}_{\mathrm{FB}}\left(\mathrm{V}_{\text {hys }}\right)$. For each stress condition, numerous devices (10) were measured. To avoid recovery-related artifacts, we kept constant and small $(100 \mathrm{~ms})$ the delay between the C-V measurements and the CVS pulses. The calculation of $\mathrm{V}_{\mathrm{FB}}$ was performed by the recently introduced inflection point technique[33].

\section{Results and analysis}

a. Capacitance - Voltage Measurements

Figure 1(a) and (b), show the C-V curves at $200 \mathrm{kHz}$ for both sets of samples, as deposited (noFGA samples) and with post deposition forming gas annealing (FGA samples). In both cases, the differences between the various $\mathrm{Hf}$ based high-k dielectrics in terms of the dielectric constant are noticeable. Considering that the total thickness of the dielectric stack measured by TEM[28] remains the same for all the stacks $\approx 7 \mathrm{~nm})$, the variation of accumulation capacitance values corresponds to different dielectric constants. The effective dielectric constant for $\mathrm{GeO}_{2} / \mathrm{Al}_{2} \mathrm{O}_{3} / \mathrm{HfMO}_{x}$ multi-layers was found in [28] to be 8.5, 7.7 and 9.5 for $\mathrm{HfMO}_{x}$ being $\mathrm{HfO}_{2}, \mathrm{HfAlO}_{x}$ and $\mathrm{HfGdO}_{x}$, respectively. Note that due to the $\mathrm{GeO}_{2}$ inter-layer (IL) those values are lower than what it would have been expected for $\mathrm{Al}_{2} \mathrm{O}_{3} / \mathrm{HfMO}_{x}$ bilayers. Moreover, it is observed that the addition of $\mathrm{Gd}$ to $\mathrm{HfO}_{2}$ increases the effective dielectric permittivity, while Al addition decreases it [28]. This conclusion is drawn since the difference between the samples is in the top layer only.

On the other hand, Figures 1 (c) and (d) present the multi-frequency $(200 \mathrm{~Hz}-300 \mathrm{~K} \mathrm{~Hz}) \mathrm{C}-\mathrm{V}$ curves measured at room temperature for the no-FGA and $\mathrm{FGA} \mathrm{HfO}_{2}$ samples, respectively. A larger frequency 
This manuscript was accepted by J. Appl. Phys. Click here to see the version of record.

Publishidigoersion is observed for the no- $\mathrm{FGA} \mathrm{HfO}_{2}$ (Figure 1(c)) from depletion into accumulation with respect to its FGA counterpart (Figure 1(d)) in the same biasing region. This indicates that FGA leads to the effective passivation of defects with energies lying near the Ge valence band (VB)[21]. The $\mathrm{HfGdO}_{x}$ and $\mathrm{HfAlO}_{\mathrm{x}}$ samples are not plotted in the figure because they have similar behavior. With regard to the dispersive features (also known as the "weak inversion hump") observed in the depletion to inversion region (gate biases greater than $\mathrm{V}_{\mathrm{FB}}$ ) they are caused by trapping and detrapping of electrons and/or holes at traps with energies between approximately mid-gap and the Ge conduction band (CB), located close to the interface [21].

Given that the area under this "weak inversion hump" and the C-V stretch-out are proportional to the amount of mid-gap states[28], we observed a reduction of these states in all $\mathrm{HFMO}_{\mathrm{x}}$ samples after the FGA treatment. This is well in agreement with previous results presented by Fadida et al [28] for a set of samples with a very similar composition and also agrees with previous reports that indicate that postmetal-gate $\mathrm{FGA}\left(\mathrm{H}_{2} / \mathrm{N}_{2}\right)$ of $A L D-\mathrm{HfO}_{2}$ and $\mathrm{ALD}-\mathrm{Al}_{2} \mathrm{O}_{3}$ dielectrics significantly reduces the interface state density[21], [34], [35]. The $D_{\text {it }}$ for both FGA and no-FGA stacks, have been calculated around mid-gap using the High-Frequency - Low-Frequency (Castagné-Vapaille) and conductance methods[36]-[38]. The inset of Figure $1(\mathrm{a})$, shows the $\mathrm{D}_{\text {it }}$ profile around mid-gap for the case of $\mathrm{HfO}_{2}$ as the high-K dielectric as function of the surface potential $\Psi_{s}$, calculated according to the Berglund's Integral[36] for the HF-LF method, and by the trap response time estimated with the Shockley-Read-Hall statistics of capture and emission rates for the conductance method[38]. It reveals that for both the HF-LF and conductance methods, the no-FGA samples are the most defective. As well as it happens with the Multi-Frequency C-V curves, Dit for the $\mathrm{HfGdO}_{x}$ and $\mathrm{HfAlO}_{x}$ samples are not plotted in the figure because they have a very similar behavior to the $\mathrm{HfO}_{2}$ samples.

It should be pointed out that, for both extraction methods, no clear differences can be observed between the stacks with different HK oxides deposited on top of the IL. This observation points towards the fact that in our samples, the IL $\left(\mathrm{GeO}_{x} / \mathrm{GeO}_{2} / \mathrm{Al}_{2} \mathrm{O}_{3}\right.$ stack of $\approx 3 \mathrm{~nm}$ measured in [28]) effectively screens the effects of HK defects on the quality of the MOS stack in terms of $D_{i t}[39]$, [40], due to its $3 n m$ thickness. In this scenario, the discussion is centered on the effects of FGA on the degradation characteristics of the samples under voltage stress, and not on the influence of the HK layer.

Finally, it is worth noting that although both the Castagné-Vapaille (HF-LF)[37] and conductance[36] methods at room temperature (RT) vary in their accuracy when they are used to evaluate $D_{\text {it }}$ near the band gap edges for low band-gap semiconductors, they have been widely used in the literature 
This manuscript was accepted by J. Appl. Phys. Click here to see the version of record.

Publishitiggevaluate $D_{\text {it }}$ around mid-gap[28], [41]-[45]. In this study, both techniques were employed to make a relative comparison of the $D_{\text {it }}$ at mid-gap [28], [38], [41] before and after the FGA. Moreover, the results obtained are consistent with recent reports [21], [24], [38], [41].

\section{b. Electrical stress measurements}

To clarify the role of the post deposition forming gas annealing (FGA) in the electrical stress measurements, the degradation characteristics of $\mathrm{Al}_{2} \mathrm{O}_{3} / \mathrm{HfMO}_{x}$ multi-layers under constant voltage stress (CVS) are studied in terms of the relative shift in $\mathrm{V}_{\mathrm{FB}}\left(\Delta \mathrm{V}_{\mathrm{FB}}\right)$ as function of the stress voltage pulse of short duration $(\approx 1 \mathrm{~s})$, at positive and negative bias. For negative bias, $V_{F B}$ was measured from consecutive $C-V$ curves at $200 \mathrm{kHz}$ while decreasing in each C-V hysteresis loop the minimal DC bias point in accumulation (namely, the stress voltage in Figure $2(a), V_{\text {stress }}$ ), but keeping the same maximal DC bias point in inversion (namely, the start voltage in Figure 2(a), $\mathrm{V}_{\text {start }}$ ). The resulting $\mathrm{C}-\mathrm{V}$ plots for the $\mathrm{HfO}_{2}$ samples can be observed in Figures 2(a) to 2(d) (FGA and no-FGA, positive and negative bias stress) and the measurement methodology is depicted in Figure 2(e). $\Delta \mathrm{V}_{\mathrm{FB}}$ was calculated as $\Delta \mathrm{V}_{\mathrm{FBN}}=\mathrm{V}_{\mathrm{FBN}}-\mathrm{V}_{\mathrm{FBO}}$, with $\mathrm{V}_{\mathrm{FBN}}$ being the flat band voltage extracted from the $\mathrm{n}^{\text {th }} \mathrm{CV}$-curve in the inversion to accumulation sweep, and $\mathrm{V}_{\mathrm{FBO}}$ the flat band voltage extracted from the first inversion to accumulation sweep. Then, a positive $\Delta V_{F B}$ represents a shift in $V_{F B}$ towards positive bias, while a negative $\Delta V_{F B}$ the opposite. Since the recovery of trapped charge for the $\mathrm{Al}_{2} \mathrm{O}_{3} / \mathrm{HfMO}_{x}$ bilayered MOS system can be fast[24], [46], special attention was paid to keep the delay between measurements constant and small (100 ms). This methodology, extensively used to stress MOS stacks[18], [25], [46], [47], allows short delay times between voltage steps, maximizing the speed of the sweep for the available instruments, thus reducing the percentage of trapped charge removed during the delay time and avoiding recovery-related artifacts[25],[46].

Figure 3(a) shows the effect of $V_{\text {stress }}$ on the shift of $V_{F B}$ for all the sets. $V_{F B}$ shift towards negative bias (negative $\triangle V_{F B}$ ) indicates hole trapping. Among annealed samples (i.e. FGA samples), a similar shift of $\mathrm{V}_{\mathrm{FB}}$ is observed as function of the stress voltage $\left(\mathrm{V}_{\text {stress }}\right)$, which is clearly smaller than the shift in the noFGA samples. Similarly, Figure $3(\mathrm{~b})$ shows the evolution of $\Delta \mathrm{V}_{\mathrm{FB}}$ measured from consecutive $\mathrm{C}-\mathrm{V}$ curves at $200 \mathrm{kHz}$ while increasing the maximal DC bias point in inversion (namely, the start voltage in Figure 3(b), $\left.\mathrm{V}_{\text {start }}\right)$, and keeping the same minimal DC bias point in accumulation $\left(\mathrm{V}_{\text {stress }}\right)$ (see Figures $2(\mathrm{~b})$ and $(\mathrm{d})$ ). Contrary to the previous case, $\mathrm{V}_{\mathrm{FB}}$ shift towards positive bias (positive $\Delta \mathrm{V}_{\mathrm{FB}}$ ) indicates accumulation of negative charge. Moreover, the no-FGA and FGA samples show the same trend.

On the other hand, Figure 3(c) and (d) show the relative variation of the C-V hysteresis voltage measured at $\mathrm{V}_{\mathrm{FB}}$ from $\mathrm{C}-\mathrm{V}$ curves in retrace mode, sweeping the gate bias from inversion to accumulation 
Publishiang back to inversion ( $\mathrm{C}-\mathrm{V}$ hysteresis loop) using the same methodology as for the measurements of $\mathrm{V}_{\mathrm{FB}}$. $\Delta \mathrm{V}_{\text {Hys }}$ was calculated as $\Delta \mathrm{V}_{\mathrm{Hys}}=\mathrm{V}_{\mathrm{HysN}}-\mathrm{V}_{\mathrm{HySO}}$, with $\mathrm{V}_{\mathrm{HysN}}$ being the Hysteresis voltage extracted from the $\mathrm{n}^{\text {th }}$ $\mathrm{CV}$-curve hysteresis loop, and $\mathrm{V}_{\text {Hys }}$ the hysteresis voltage extracted from the first hysteresis loop. Then, a positive $\Delta \mathrm{V}_{\text {Hys }}$ represents an increase in the hysteresis width. Figure 3(c) shows the effect of the minimum bias in accumulation ( $\mathrm{V}_{\text {stress }}$ ) on the width of the $\mathrm{C}-\mathrm{V}$ hysteresis, while keeping the same starting DC bias point in inversion $\left(\mathrm{V}_{\text {start }}\right)$. It is observed that the no-FGA samples show higher $\Delta \mathrm{V}_{\text {hys }}$ as $\mathrm{V}_{\text {stress }}$ increases, although such difference is not as large as in the case of $\Delta \mathrm{V}_{\mathrm{FB}}$ (Figure $3(\mathrm{a})$ ). However, if $\Delta \mathrm{V}_{\text {hys }}$ is measured in consecutive $C-V$ curves while increasing the maximal $D C$ bias point in inversion $\left(V_{\text {start }}\right)$, with the same minimal $D C$ bias point in accumulation $\left(\mathrm{V}_{\text {stress }}\right)$, the $\Delta \mathrm{V}_{\text {hys }}$ increases without significant variations between no-FGA and FGA samples. Therefore, the main difference between FGA and no-FGA samples arises for the case of the negative stress. To exclude any hot carrier injection mechanism to be responsible for such variations, Current-Voltage curves of the samples are shown in Figure $4(a)$ and (b), for no-FGA and FGA samples, respectively. It can be seen that for the voltage range (0 to $-4 \mathrm{~V}$ approx.) applied to the stacks during the stress, the current through it does not surpass the $1 \mathrm{nA}$ limit.

\section{c. Stress as function of time}

In order to assess the influence of the stressing time and confirm the results obtained under stress at negative bias in Figure 3(a), the evolution of the flat-band voltage was studied as function of the stress time at a constant voltage. This was done by applying a constant $V_{G}-V_{F B}$ voltage, while measuring the $C$ $V$ hysteresis curve in the retrace mode (where the voltage was swept from inversion to accumulation and then back to inversion) at regular intervals[18]. Following a similar procedure, C-V hysteresis curves were also measured during a recovery process at room temperature (RT) without biasing the stack, which followed the previously mentioned CVS. The results obtained are presented in Figure 5(a) and (b), and it is interesting to note that $V_{\mathrm{FB}}$ shift is always more significant in the case of the non-annealed samples (noFGA samples). Furthermore, the shift towards negative bias of the flat-band voltage suggests the accumulation of positive charge in the gate oxide confirming the results of Figure 3. Measurements of the $V_{\mathrm{FB}}$ shift (Figure $5(\mathrm{a})$ ) here presented have been fitted by an exponential law $\Delta V_{F B}=A e^{\left(-\frac{t}{\tau}\right)}$ in both the stressing and recovery periods (fits not shown), revealing time constants of around 20 to 100 seconds in the stressing period (from 0 to $750 \mathrm{sec}$. approx.), and 200 to 600 seconds in the recovery part (from 750 to $150 \mathrm{sec}$. approx.). In this manner, not only is the recovery process incomplete, but also slower than the degradation process (it takes longer for the samples to partially recover). 
It should be noted that the current level for the bias used in Figure $5\left(V_{G}-V_{F B}=-3.5 V\right)$ is in the order of 100pA for both sets of samples (see I-V measurements shown in Figure 4)to avoid charge buildup due to higher leakage currents.

Moreover, we also observe recovery of the flat band voltage during the RT relaxation without biasing the stack. Although the recovery of $\mathrm{V}_{\mathrm{FB}}$ after CVS is not the scope of this work, the magnitude of this effect is consistent with earlier reports[18]. The characteristic time during the annealing phase is very long, as it takes some minutes for the partial recovery of $\mathrm{V}_{\mathrm{FB}}$. Therefore, it is clear from this observation that the small values of delay $(100 \mathrm{~ms})$ between measurements will not affect the main observation of our work: flat band voltage shift is larger in the case of the no-FGA samples when compared to the FGA ones, for the same stressing conditions at negative bias (Figure 3 (a) and (c), and Figure5).

It's worth noting that the degradation dynamics of stacks with different HK oxides show differences that are well in agreement with the literature: for $\mathrm{HfO}_{2}$, the $\mathrm{C}-\mathrm{V}$ hysteresis is wider and it is strongly reduced after FGA process, while though for ternary oxides the reduction is still observed, the effects are not as pronounced[48]. The origin of such differences, possibly related to deep trapping and bulk oxide defects, is not on the scope of this work.

\section{Discussion}

By comparing the dynamics of $\mathrm{V}_{\mathrm{FB}}$ and the $\mathrm{C}-\mathrm{V}$ hysteresis, relevant observations can be made regarding the role of the post deposition FGA in the degradation characteristics under voltage stress. At negative bias, Figure $3(\mathrm{a})$ and $(\mathrm{c})$, the $\mathrm{V}_{\mathrm{FB}}$ and $\mathrm{V}_{\text {hys }}$ as function of $\mathrm{V}_{\mathrm{stress}}-\mathrm{V}_{\mathrm{FB}}$ show different behavior between both set of samples (FGA and no-FGA samples). In the FGA samples, the $V_{\text {hys }}$ shows a monotonous increase up to $+0.4 \mathrm{~V}$ in the bias range from $-1.5 \mathrm{~V}$ to $-3.5 \mathrm{~V}$, while $\mathrm{V}_{\mathrm{FB}}$ does not show relevant variations $(<0.1 \mathrm{~V})$ in the same bias range. This is coherent with the fact that the repeated $C-V$ hysteresis sweeps overlap the 1st C-V hysteresis in the upward sweep direction (Figure 2(c)), when the MOS capacitor is measured from inversion to accumulation (small $\mathrm{V}_{\mathrm{FB}}$ variations), indicating that the majority of charge trapping is a reversible process. On the contrary, no-FGA samples show a much steeper decrease of $\mathrm{V}_{\mathrm{FB}}$ while the $\mathrm{C}-\mathrm{V}$ hysteresis also increases, indicating that the positive charge trapping is permanent. This difference in the level of hole trapping is also observed in Figure 5(a) and (b), where the no-FGA samples clearly exhibit a higher level of hole trapping.

The permanent characteristic of the charge trapping observed in the no-FGA samples, may be related to a higher barrier for the trapped holes to be removed from the traps[32]. On the other hand, 
This manuscript was accepted by J. Appl. Phys. Click here to see the version of record.

Publishithg higher level of positive charge trapping in the no-FGA samples compared to their FGA counterparts may be related to a higher density of hole traps with energy levels aligned with the semiconductor valance band edge (i.e. negative bias on the gate contact on Ge-p substrate). In a recent paper, Zhang et al[21] reported direct experimental evidence using Soft and Hard X-rays synchrotron photoelectron spectroscopy about the chemical states of germanium in the Ge/ALD- $\mathrm{Al}_{2} \mathrm{O}_{3}$ region during FGA. It shows that the Germanium oxide $\left(\mathrm{GeO}_{x}\right.$, Germanium in oxidation states lower than +4$)$ formed at the high$\mathrm{K} /$ semiconductor interface can significantly degrade the electrical quality of the entire structure by introducing traps at energy levels near the Conduction Band (CB) (namely, electron traps) and Valence Band (VB) (namely, hole traps). Nevertheless, it is also shown that such traps are selectively passivated during the forming gas annealing.

In this regard, the experimental evidence in Ref. [21] leads to a model which proposes that, during FGA, hydrogen (present in the forming gas atmosphere) may diffuse to the $\mathrm{Al}_{2} \mathrm{O}_{3} / \mathrm{Ge}$ interface and react with residual hydroxyls incorporated during the growth of the ALD-Al $\mathrm{O}_{3}$, producing $\mathrm{H}_{2} \mathrm{O}$. The water molecules thus formed can further react with $\mathrm{Ge}$ and $\mathrm{GeO}_{x}$ to form $\mathrm{GeO}_{2}$ (a less defective $\mathrm{Ge}$ oxide) reducing the density of defects at the interface. It is worth to mention that this proposed reaction is consistent with prior experiments on high-k oxides on Ge substrates[10], [23], and that the existence of $\mathrm{GeO}_{x}$ in $\mathrm{HF}$ cleaned substrates prior FGA, has been widely documented in the literature[30], [49], [50]. Also, the Pt gate helps to dissociate $\mathrm{H}_{2}$ to atomic $\mathrm{H}$, which may contribute to the reaction with the $-\mathrm{OH}$ group in the $\mathrm{ALD}-\mathrm{Al}_{2} \mathrm{O}_{3}$ and, therefore, to $\mathrm{GeO}_{2}$ formation.

Additionally, the interface bonding configuration between Ge and an overlying suboxide or oxide layer, has been also studied by first-principles modeling by Zhang et al in [21]. The results show that $\mathrm{Ge} / \mathrm{GeO}_{2}$ has a defect free interface within the $\mathrm{Ge}$ band gap, while the $\mathrm{Ge} / \mathrm{GeO}_{x} / \mathrm{GeO}_{2}$ structure can have a large density of defect states (O deficiency defects) with energy levels near the CB (electron traps) and VB (hole traps) edges, which agrees well with the existing literature[34], [35]. Furthermore, hydrogen also reacts with these defects, removing both the electron and hole traps from the band gap energy range[21].

For positive bias stress, shown in Figure $3(b)$ and (d), where the $V_{F B}$ and $V_{\text {hys }}$ are studied as function of $V_{\text {start, }}$ both parameters show a monotonous increase without differences between FGA and no-FGA samples, indicating accumulation of negative charge. This may suggest that the electron trapping $\left(\mathrm{V}_{\mathrm{FB}}\right.$ shift towards positive bias) happening for the positive stress is being caused by traps generated during the voltage stress. This interpretation is supported by the increase in $\Delta \mathrm{D}_{\mathrm{it}}$ around mid-gap (this is, the increase of $D_{\text {it }}$ with respect to the $D_{\text {it }}$ around mid-gap for the fresh samples) estimated for the sample being stressed during each single frequency capacitance voltage loop measurement performed during the CVS stress, 
Publishiang the results are summarized in the inset of Figure 2(d). It shows that for positive stress the increase in $D_{i t}$ is larger than for the negative stress, indicating that when charge is injected from the substrate, the damage in the interface results more significant.

As previously mentioned, $\mathrm{H}$ present in the FGA atmosphere reacts with the defects at the $\mathrm{Ge} / \mathrm{GeO}_{\mathrm{x}} / \mathrm{GeO}_{2}$ interface removing both the electron and hole traps from the band gap energy range. However, the energy barrier for removing those different trap states (holes and electrons) is not the same, being larger the energy required for electron traps passivation [21], [51]. Thus, the reduced impact of the FGA on the passivation of electron trap states, may also contribute to the lack of differences between FGA and no-FGA samples stressed at positive bias.

Summarizing the overall results, it is observed that the stress at negative and positive bias contribute with hole and electron trapping respectively, based on the shift of the $\mathrm{V}_{\mathrm{FB}}$. The main feature occurs at negative bias, where strong dependence on the FGA process is observed. It is worth mentioning that there is a common trend regardless of the $\mathrm{HfMO}_{x}$ stack deposited on top of the $\mathrm{GeO}_{x} / \mathrm{GeO}_{2} / \mathrm{Al}_{2} \mathrm{O}_{3}$ IL growth on top of the $\mathrm{Ge}$ substrate. This indicates that the $\mathrm{GeO}_{x} / \mathrm{GeO}_{2} / \mathrm{Al}_{2} \mathrm{O}_{3} \mathrm{IL}$ may play a determinant role in the dependence on the FGA process. Nevertheless, the thickness of the $\mathrm{GeO}_{x} / \mathrm{GeO}_{2} / \mathrm{Al}_{2} \mathrm{O}_{3}$, around 3 $\mathrm{nm}$, may be too large for the $\mathrm{HfMO}_{\mathrm{x}}$ layer to influence the charge trapping phenomena[39], [40], which is usually assumed to happen in the vicinity of the interface. Further investigation with thinner ILs should be made in order to clarify the impact of these various HK materials.

\section{Conclusions}

The influence of forming gas annealing on the degradation under voltage stress of multi-layered germanium-based Metal-Oxide-Semiconductor capacitors ( $\mathrm{p}-\mathrm{Ge} / \mathrm{GeO}_{x} / \mathrm{Al}_{2} \mathrm{O}_{3} / \mathrm{High}-\mathrm{K} / \mathrm{Metal}$ Gate) has been analyzed in terms of the $\mathrm{C}-\mathrm{V}$ hysteresis and flat band voltage shift as function of both negative and positive stress fields.

Regardless of the stress field and duration of the stress pulse, it is observed that the stress at negative and positive bias contributes with hole and electron trapping respectively. The main feature occurs under negative bias stress, where strong dependence on the FGA process is observed.

The possible reasons for a higher level of positive charge trapping in the no-FGA samples compared to the FGA samples at negative stress fields is related to a higher density of hole traps with energy levels aligned with the semiconductor valance band edge. The FGA produces a selective passivation of traps at 
This manuscript was accepted by J. Appl. Phys. Click here to see the version of record.

Publishith interfacial layer with energy levels near the Conduction Band (electron traps) and Valence Band

(hole traps) edges, with the energy barrier being smaller for the passivation of the latter.

Finally, it is worth mentioning the challenges arising from this behavior when addressing the hybrid integration of Ge technologies with III-V substrates. For the latter, surface treatment is almost mandatory in order to achieve a reduced $D_{\text {it }}$ profile, however it contributes to the charge generation in the dielectric stack, mainly because of the de-passivation of the traps at the dielectric/semiconductor interface. This implies that the improvement of the high-K/InGaAs interface does not necessarily mean an increase of the reliability of the MOS stack. On the contrary, Ge-based MOS stacks show a different behavior, where FGA reduces both the $D_{\text {it }}$ and the charge trapping in Ge stacks, affecting the shift of the flat band voltage. Therefore, summarizing the experimental results presented in this paper regarding Ge based MOS stacks, and taking into account previous literature about the degradation mechanisms in InGaAs -based MOS stacks, we find that a final post metallization forming gas $\left(\mathrm{H}_{2} / \mathrm{N}_{2}\right)$ annealing step may affect the degradation rate of Ge and InGaAs based MOS stacks in a different way. While charge trapping is reduced in $\mathrm{HK} / \mathrm{GeO}_{2} / \mathrm{Ge}$ stacks after FGA, the opposite is observed in $\mathrm{HK} / \mathrm{InGaAs}$ stacks. Proper FGA conditions to improve the HK/semiconductor interface without affecting the stack's reliability are therefore a key to unleash the development of hybrid technologies.

The results presented in this paper contribute to a better understanding of the limiting factors of Ge and III-V (InGaAs) channel devices on a silicon substrate, paving the way for a high performance low power CMOS technology of high mobility channel materials on Si.

\section{Acknowledgements}

This work was funded by the Argentinean Ministry of Science and Technology (MINCYT) under Contract PICT2013/1210, the National Council for Scientific and Technical Research (CONICET) under Project PIP-11220130100077CO and the Buenos Aires Regional Faculty of the National Technological University (UTN.BA) under Project PID-UTN2014/UT12423. The authors greatly acknowledge Laura Nyns, Dennis Lin, Sven Van Elshocht, and Matty Caymax from IMEC for providing the samples.

\section{References}

[1] A. W. Strong et al., Reliability Wearout Mechanisms in Advanced CMOS Technologies (IEEE Press Series on Microelectronic Systems), 1st ed. Wiley-IEEE Press, 2009.

[2] S. Takagi, R. Zhang, T. Hoshii, N. Taoka, and M. Takenaka, "MOS Interface Control Technologies for III-V/Ge Channel MOSFETs," in ECS Transactions, 2011, vol. 41, no. 3, pp. 3-20.

[3] S. Takagi and M. Takenaka, "Advanced non-Si channel CMOS technologies on Si platform," in 2010 10th IEEE International Conference on Solid-State and Integrated Circuit Technology, 2010, 
This manuscript was accepted by J. Appl. Phys. Click here to see the version of record.

pp. 50-53.

[4] J. A. del Alamo, "Nanometre-scale electronics with III-V compound semiconductors," Nature, vol. 479, no. 7373, pp. 317-323, Nov. 2011.

[5] Chi On Chui, Hyoungsub Kim, P. C. McIntyre, and K. C. Saraswat, "A germanium NMOSFET process integrating metal gate and improved high-K dielectrics," in IEEE International Electron Devices Meeting 2003, 2003, p. 18.3.1-18.3.4.

[6] "ITRS 2.0 Executive Report," 2015.

[7] D. P. Brunco et al., "Germanium MOSFET Devices: Advances in Materials Understanding, Process Development, and Electrical Performance," J. Electrochem. Soc., vol. 155, no. 7, p. H552, 2008.

[8] M. Heyns et al., "Advancing CMOS beyond the Si roadmap with Ge and III/V devices," in 2011 International Electron Devices Meeting, 2011, p. 13.1.1-13.1.4.

[9] L. Czornomaz et al., "First demonstration of InGaAs/SiGe CMOS inverters and dense SRAM arrays on Si using selective epitaxy and standard FEOL processes," in 2016 IEEE Symposium on VLSI Technology, 2016, pp. 1-2.

[10] Y. Oshima et al., "Chemical Bonding, Interfaces, and Defects in Hafnium Oxide/Germanium Oxynitride Gate Stacks on Ge(100)," J. Electrochem. Soc., vol. 155, no. 12, p. G304, Dec. 2008.

[11] P. Batude et al., "Insights on fundamental mechanisms impacting Ge metal oxide semiconductor capacitors with high-k/metal gate stacks," J. Appl. Phys., vol. 102, no. 3, p. 34514, Aug. 2007.

[12] M. Heyns et al., "Challenges for introducing Ge and III/V devices into CMOS technologies," in 2012 IEEE International Reliability Physics Symposium (IRPS), 2012, p. 5D.1.1-5D.1.10.

[13] T. D. Lin et al., "Realization of high-quality HfO 2 on In 0.53 Ga 0.47 As by in-situ atomic-layerdeposition," Appl. Phys. Lett., vol. 100, no. 17, p. 172110, Apr. 2012.

[14] H. D. Trinh et al., "The influences of surface treatment and gas annealing conditions on the inversion behaviors of the atomic-layer-deposition Al2O3/n-In0.53Ga0.47As metal-oxidesemiconductor capacitor," Appl. Phys. Lett., vol. 97, no. 4, p. 42903, Jul. 2010.

[15] É. O’Connor, S. Monaghan, K. Cherkaoui, I. M. Povey, and P. K. Hurley, "Analysis of the minority carrier response of $\mathrm{n}$-type and $\mathrm{p}$-type $\mathrm{Au} / \mathrm{Ni} / \mathrm{Al} 2 \mathrm{O} 3 / \mathrm{In} 0.53 \mathrm{Ga} 0.47 \mathrm{As} / \mathrm{InP}$ capacitors following an optimized (NH 4 ) 2 S treatment," Appl. Phys. Lett., vol. 99, no. 21, p. 212901, Nov. 2011.

[16] I. Krylov, A. Gavrilov, M. Eizenberg, and D. Ritter, "Correlation between Ga-O signature and midgap states at the Al203/In0.53Ga0.47As interface," Appl. Phys. Lett., vol. 101, no. 6, p. 63504, 2012.

[17] F. Palumbo and M. Eizenberg, "Degradation characteristics of metal/Al 203 /n-InGaAs capacitors," J. Appl. Phys., vol. 115, no. 1, p. 14106, Jan. 2014.

[18] F. Palumbo, I. Krylov, and M. Eizenberg, "Comparison of the degradation characteristics of AION/InGaAs and Al2O3/InGaAs stacks," J. Appl. Phys., vol. 117, no. 10, p. 104103, 2015.

[19] Chi On Chui, Hyoungsub Kim, D. Chi, B. B. Triplett, P. C. McIntyre, and K. C. Saraswat, "A sub$400^{\circ} \mathrm{C}$ germanium MOSFET technology with high-k dielectric and metal gate," in Digest. International Electron Devices Meeting, 2002, pp. 437-440.

[20] D. Bodlaki, H. Yamamoto, D. H. Waldeck, and E. Borguet, "Ambient stability of chemically passivated germanium interfaces," Surf. Sci., vol. 543, no. 1-3, pp. 63-74, Oct. 2003.

[21] L. Zhang et al., "Selective Passivation of GeO 2 /Ge Interface Defects in Atomic Layer Deposited High- k MOS Structures," ACS Appl. Mater. Interfaces, vol. 7, no. 37, pp. 20499-20506, Sep. 2015.

[22] Q. Xie et al., "Germanium surface passivation and atomic layer deposition of high- k dielectricsa tutorial review on Ge-based MOS capacitors," Semicond. Sci. Technol., vol. 27, no. 7, p. 74012, Jul. 2012.

[23] S. Swaminathan, Y. Sun, P. Pianetta, and P. C. Mclntyre, "Ultrathin ALD-Al 203 layers for Ge(001) gate stacks: Local composition evolution and dielectric properties," J. Appl. Phys., vol. 110, no. 9, 
This manuscript was accepted by J. Appl. Phys. Click here to see the version of record.

p. 94105, Nov. 2011.

J. Franco et al., "SiGe Channel Technology: Superior Reliability Toward Ultrathin EOT DevicesPart I: NBTI," IEEE Trans. Electron Devices, vol. 60, no. 1, pp. 396-404, Jan. 2013.

[25] J. Franco et al., "Understanding the suppressed charge trapping in relaxed- and strained$\mathrm{Ge} / \mathrm{SiO} 2 / \mathrm{HfO} 2$ pMOSFETs and implications for the screening of alternative high-mobility substrate/dielectric CMOS gate stacks," in 2013 IEEE International Electron Devices Meeting, 2013, p. 15.2.1-15.2.4.

[26] J. Franco et al., "NBTI Reliability of SiGe and Ge Channel pMOSFETs With SiO2 HfO2 Dielectric Stack," IEEE Trans. Device Mater. Reliab., vol. 13, no. 4, pp. 497-506, Dec. 2013.

[27] E. Golias, L. Tsetseris, A. Chroneos, and A. Dimoulas, "Interaction of metal impurities with native oxygen defects in GeO2," Microelectron. Eng., vol. 104, pp. 37-41, Apr. 2013.

[28] S. Fadida et al., "Hf-based high-k dielectrics for p-Ge MOS gate stacks," J. Vac. Sci. Technol. B Microelectron. Nanom. Struct., vol. 32, no. 3, p. 03D105, May 2014.

[29] S. Fadida, L. Nyns, S. Van Elshocht, and M. Eizenberg, "Effect of Remote Oxygen Scavenging on Electrical Properties of Ge-Based Metal-Oxide-Semiconductor Capacitors," J. Electron. Mater., pp. 1-7, Aug. 2016.

[30] A. Delabie et al., "Atomic Layer Deposition of High-k Dielectric Layers on Ge and III-V MOS Channels," ECS Trans., vol. 16, no. 10, pp. 671-685, Oct. 2008.

[31] L. Nyns et al., "Interface and Border Traps in Ge-Based Gate Stacks," in ECS Transactions, 2011, vol. 35, no. 3, pp. 465-480.

[32] S. Fadida, M. Eizenberg, L. Nyns, S. Van Elshocht, and M. Caymax, "Band alignment of Hf-Zr oxides on Al2O3/GeO2/Ge stacks," Microelectron. Eng., vol. 88, no. 7, pp. 1557-1559, 2011.

[33] R. Winter, J. Ahn, P. C. McIntyre, and M. Eizenberg, "New method for determining flat-band voltage in high mobility semiconductors," J. Vac. Sci. Technol. B, Nanotechnol. Microelectron. Mater. Process. Meas. Phenom., vol. 31, no. 3, p. 30604, May 2013.

[34] H. Matsubara, T. Sasada, M. Takenaka, and S. Takagi, "Evidence of low interface trap density in GeO2/Ge metal-oxide-semiconductor structures fabricated by thermal oxidation," Appl. Phys. Lett., vol. 93, no. 3, p. 32104, Jul. 2008.

[35] D. Kuzum et al., "Ge-Interface Engineering With Ozone Oxidation for Low Interface-State Density," IEEE Electron Device Lett., vol. 29, no. 4, pp. 328-330, Apr. 2008.

[36] E. H. Nicollian and J. R. Brews, MOS (metal oxide semiconductor) physics and technology. WileyInterscience, 2003.

[37] R. Castagné and A. Vapaille, "Description of the SiO2/Si interface properties by means of very low frequency MOS capacitance measurements," Surf. Sci., vol. 28, no. 1, pp. 157-193, Nov. 1971.

[38] R. Engel-Herbert, Y. Hwang, and S. Stemmer, "Comparison of methods to quantify interface trap densities at dielectric/III-V semiconductor interfaces," J. Appl. Phys., vol. 108, no. 12, p. 124101, Dec. 2010.

[39] J. Franco et al., "BTI reliability of high-mobility channel devices: SiGe, Ge and InGaAs," in 2014 IEEE International Integrated Reliability Workshop Final Report (IIRW), 2014, pp. 53-57.

[40] R. Zhang, N. Taoka, Po-Chin Huang, M. Takenaka, and S. Takagi, "1-nm-thick EOT high mobility Ge n- and p-MOSFETs with ultrathin GeOx/Ge MOS interfaces fabricated by plasma post oxidation," in 2011 International Electron Devices Meeting, 2011, p. 28.3.1-28.3.4.

[41] Chi On Chui, F. Ito, and K. C. Saraswat, "Nanoscale germanium MOS Dielectrics-part I: germanium oxynitrides," IEEE Trans. Electron Devices, vol. 53, no. 7, pp. 1501-1508, Jul. 2006.

[42] G. Dushaq, A. Nayfeh, and M. Rasras, "Passivation of Ge/high- $\boldsymbol{k}$ interface using RF Plasma nitridation," Semicond. Sci. Technol., vol. 33, no. 1, p. 15003, Jan. 2018.

[43] A. Ghosh et al., "Growth, structural, and electrical properties of germanium- on -silicon heterostructure by molecular beam epitaxy," AIP Adv., vol. 7, no. 9, p. 95214, Sep. 2017. 
A. Delabie et al., "Effective electrical passivation of $\mathrm{Ge}(100)$ for high-k gate dielectric layers using germanium oxide," Appl. Phys. Lett., vol. 91, no. 8, p. 82904, Aug. 2007.

[45] S. Kar, High Permittivity Gate Dielectric Materials, vol. 43. 2013.

[46] J. Franco et al., "Suitability of high-k gate oxides for III-V devices: A PBTI study in In0.530.47As devices with Al203," in 2014 IEEE International Reliability Physics Symposium, 2014, p. 6A.2.16A.2.6.

[47] J. Lin et al., "An investigation of capacitance-voltage hysteresis in metal/high- k /In 0.53 Ga 0.47 As metal-oxide-semiconductor capacitors," J. Appl. Phys., vol. 114, no. 14, p. 144105, Oct. 2013.

[48] I. Krylov, D. Ritter, and M. Eizenberg, " $\mathrm{Hf}_{x} \mathrm{Al}_{\mathrm{y}} \mathrm{O}$ ternary dielectrics for InGaAs based metal-oxidesemiconductor capacitors," J. Appl. Phys., vol. 122, no. 3, p. 34505, Jul. 2017.

[49] P. Ponath, A. B. Posadas, and A. A. Demkov, "Ge(001) surface cleaning methods for device integration," Appl. Phys. Rev., vol. 4, no. 2, p. 21308, Jun. 2017.

[50] B. Onsia et al., "On the Application of a Thin Ozone Based Wet Chemical Oxide as an Interface for ALD High-k Deposition," Solid State Phenom., vol. 103-104, pp. 19-22, 2005.

[51] K. M. Wong, W. K. Chim, J. Q. Huang, and L. Zhu, "Scanning capacitance microscopy detection of charge trapping in free-standing germanium nanodots and the passivation of hole trap sites," $J$. Appl. Phys., vol. 103, no. 5, p. 54505, Mar. 2008. 

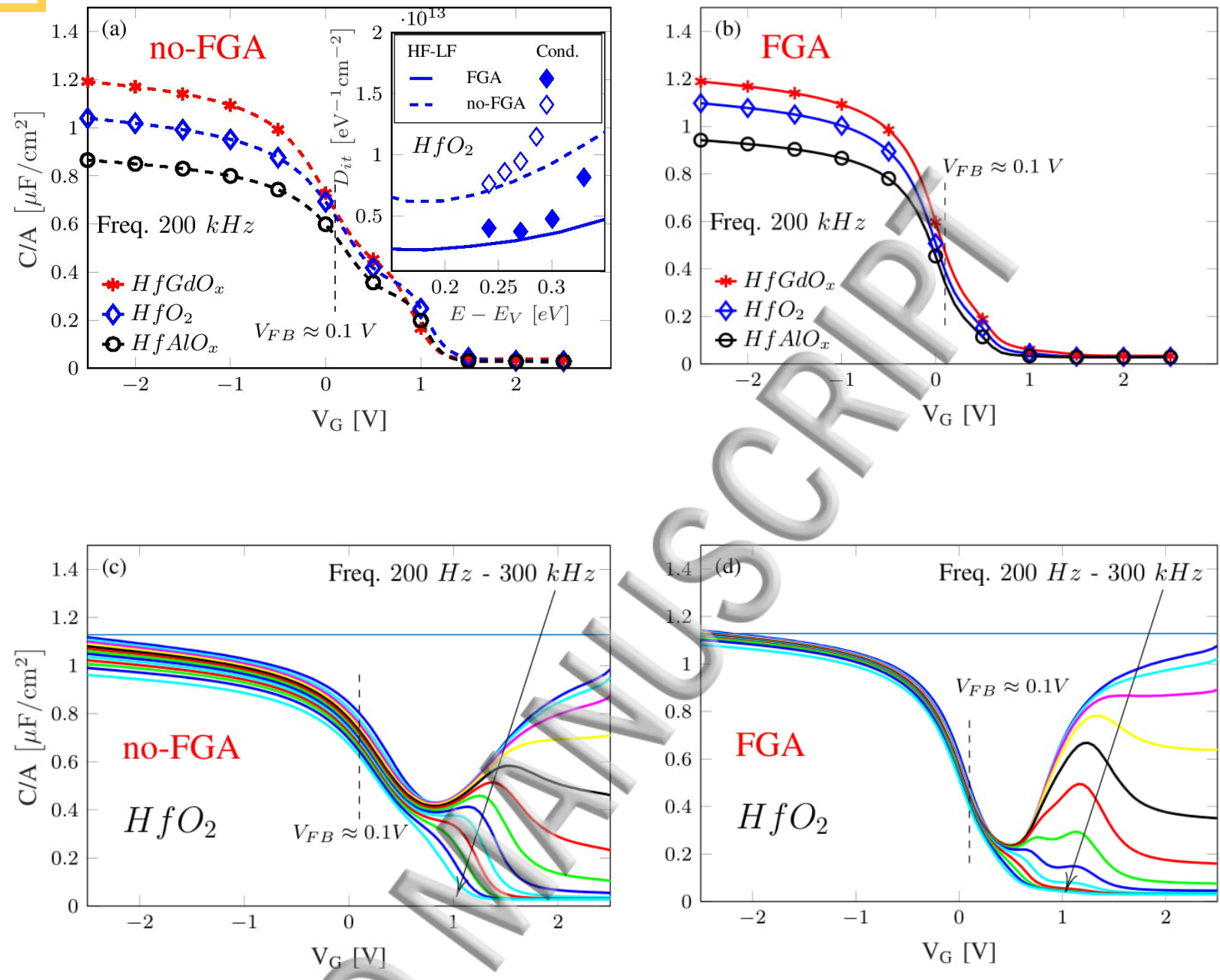

Figure 1. Capacitance - Voltage curves for the samples being studied measured at $200 \mathrm{kHz}$. (a) Samples without forming gas annealing, and (b) samples with forming gas annealing. In each plot the arrow points out the flat band voltage, calculated according to the inflection point technique. The inset in (a) shows the $D_{\text {it }}$ for the $\mathrm{HfO}_{2}$ samples calculated using the HF-LF method (dashed blueline corresponds to no-FGA and solid blue line to FGA samples) against the conductance method (filled and solid diamond markers, for noFGA and FGA, respectively). In both cases, $D_{i t}$ are higher for the no-FGA sample. Subfigures (c) y (d) shows de Multi-Frequency capacitance-voltage measurements $\left(200 \mathrm{~Hz}-300 \mathrm{kHz}\right.$ ) for $\mathrm{HfO}_{2}$ stacks, pre and post the FGA step, respectively. A reduction in the frequency dispersion in accumulation in the FGA sample is clear as well as a higher weak inversion hump, which is consistent with the reduction in $D_{i t}$. 

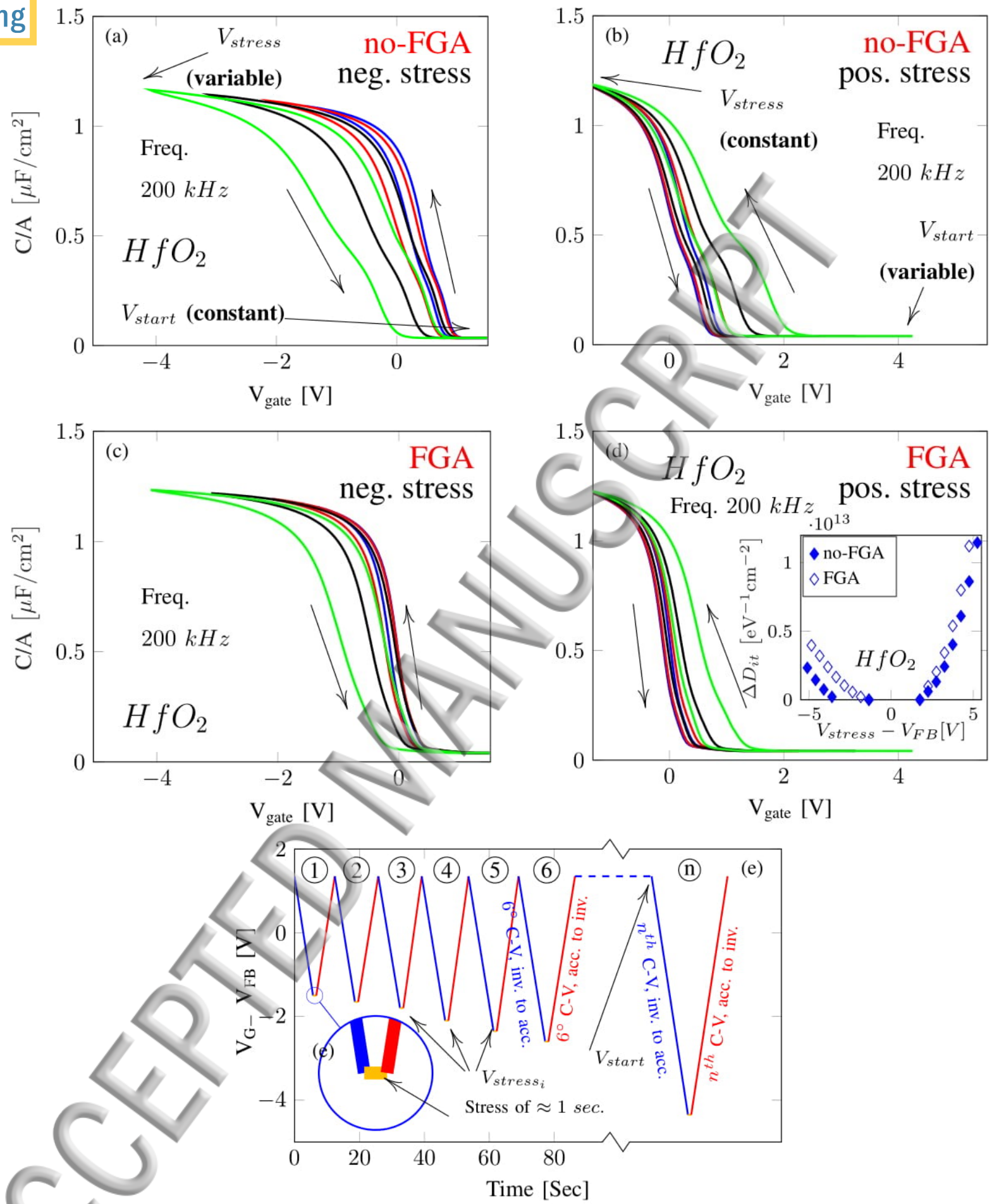

Figure 2. Single Frequency Capacitance - Voltage hysteresis measurements. Without Forming Gas Annealing (no-FGA) samples negatively (a) and positively (b) stressed. Forming Gas Annealing (FGA) samples are shown in (c) and (d) for negative and positive stress voltages. The inset of (d) shows the evolution of $D_{i t}$ as function of $V_{\text {stress }}$ and $V_{\text {start }}$ respect to the fresh sample $\left(\Delta D_{i t}\right)$ for each stress calculated at mid-gap. The evolution of the stressing voltage is shown in (e) for the case of the negative voltage stress, along the consecutive $C$-V loops. $V_{\text {stress }}$ and $V_{\text {start }}$ are also pointed in figures ( $\left.a\right)$ and (b) for the negative and positive voltage stress, respectively. 

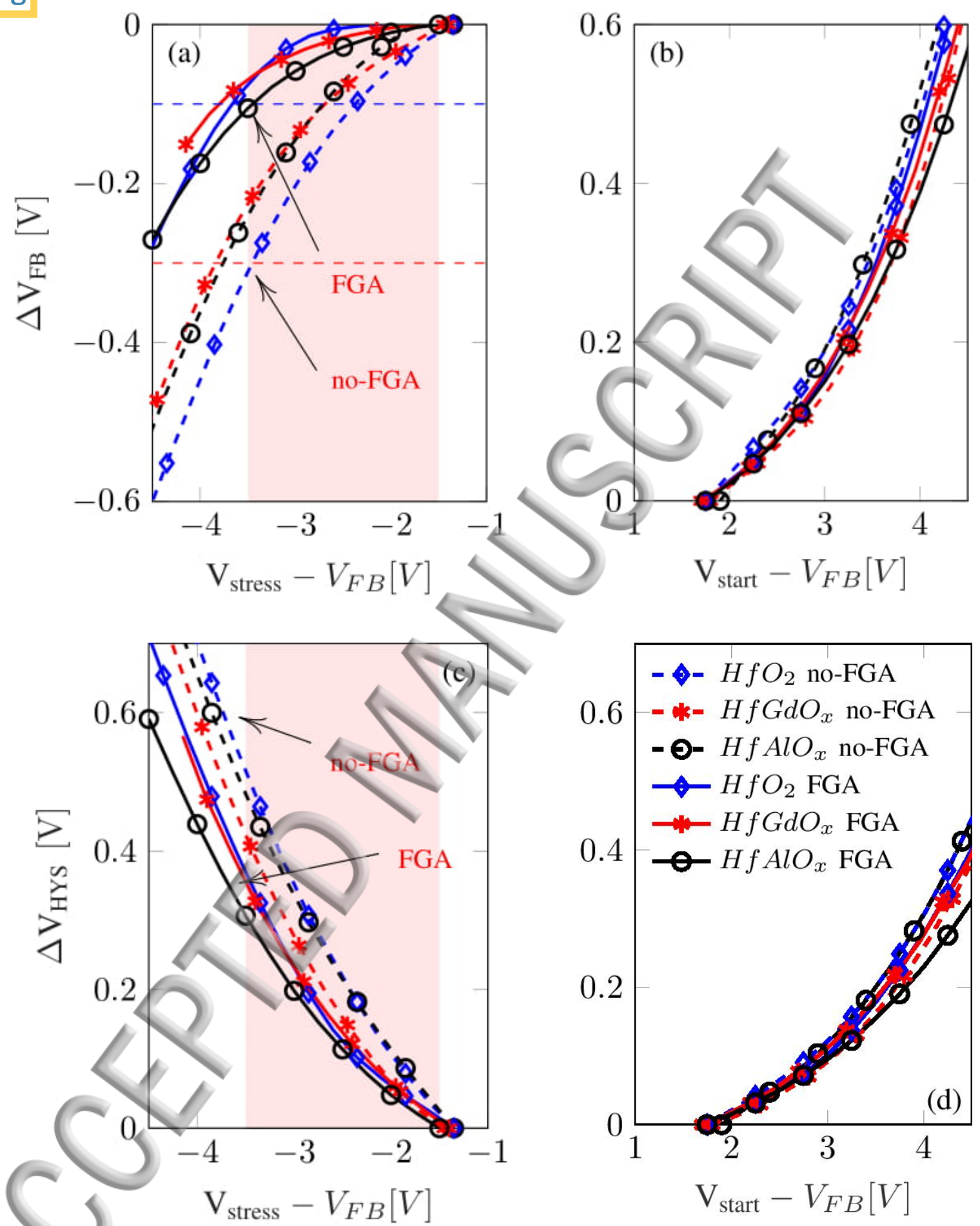

Figure 3. $\Delta \mathrm{V}_{\mathrm{FB}}$ and $\Delta \mathrm{V}_{\mathrm{Hys}}$ for the different multi-layered samples for negative and positive voltage stress (decreasing $V_{\text {stress }}$ and increasing $V_{\text {start }}$, respectively). Samples without FGA stressed with negative (a) and positive (b) bias. Samples without FGA with negative (c) and positive (d) bias. Red and blue dashed lines indicate in (a) the maximal variation of the $\mathrm{V}_{\mathrm{FB}}$ in the range of $-3.5 \mathrm{~V}$ to $-1.5 \mathrm{~V}$ (shadowed zone) for noFGA and FGA, respectively. 

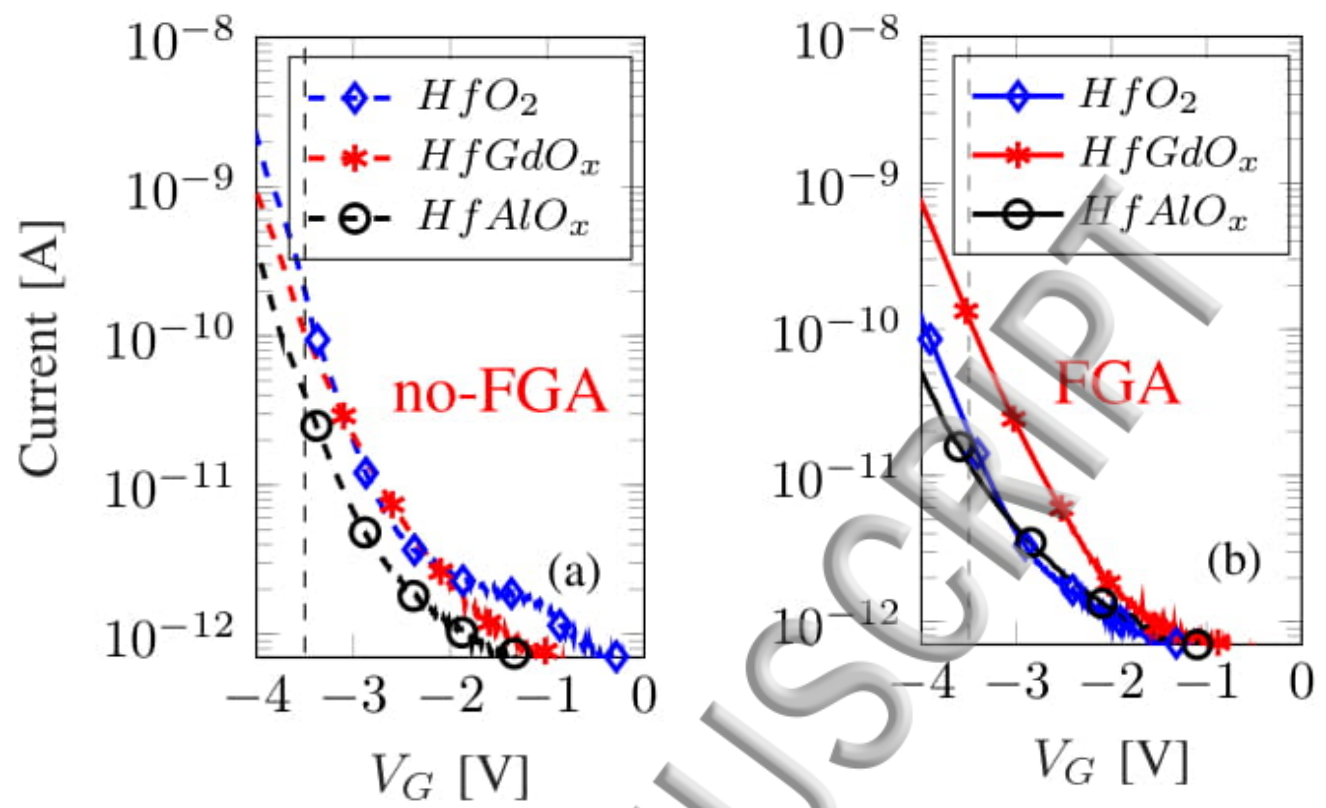

Figure 4. Voltage-Current measurements. (a) no-FGA samples, (b) FGA samples. Current results slightly higher for no-FGA samples. 

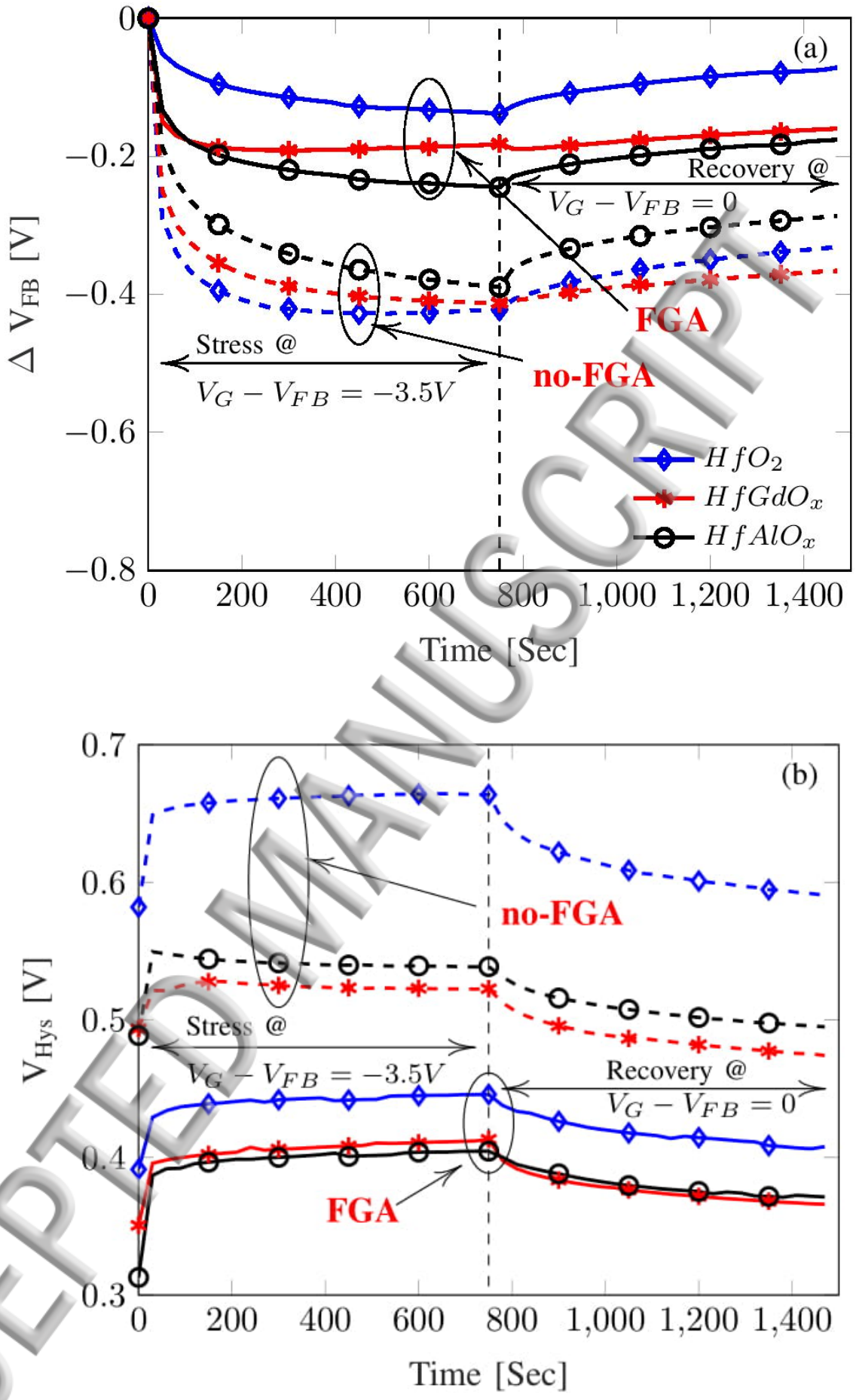

Figure 5. Impact of FGA on the $V_{F B}$ shift (a) and C-V hysteresis (b) of the different stacks for longer stressing times (30 sec.). It can be seen how the FGA reduces both the $\Delta V_{F B}$ and the $V_{\text {hys }}$ in all sets of samples. 


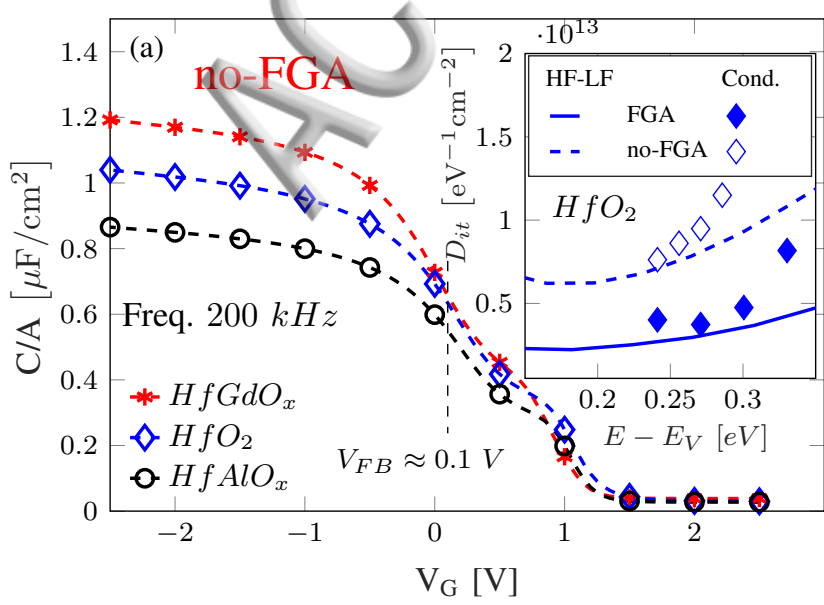




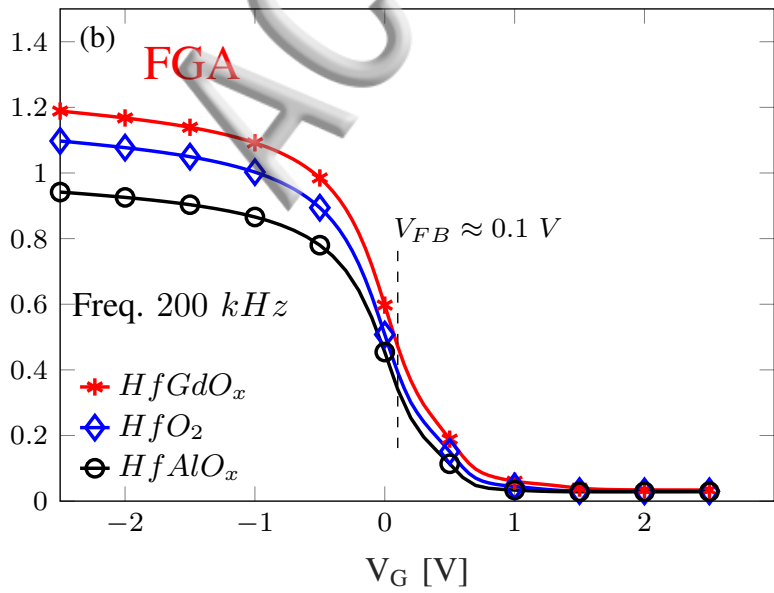




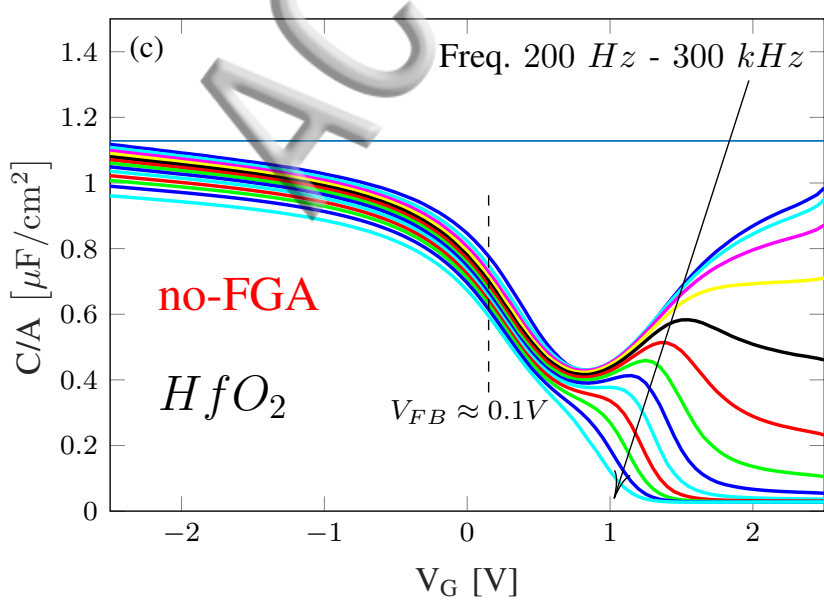




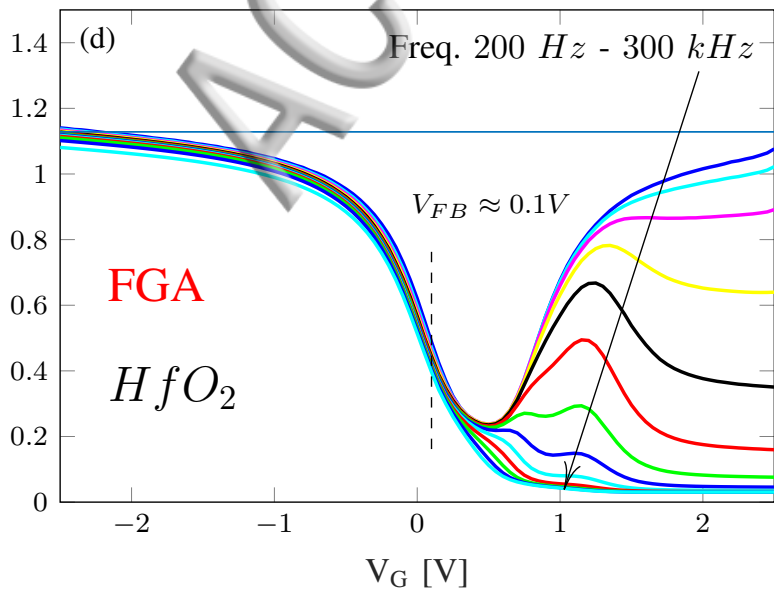




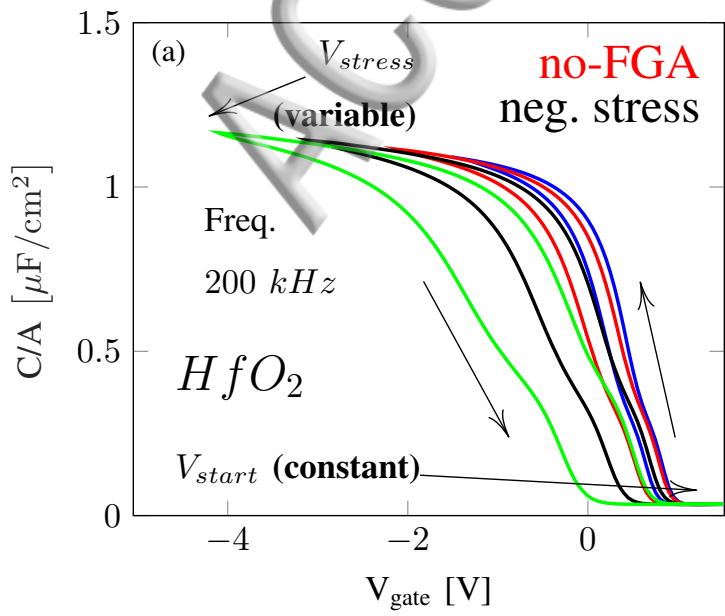




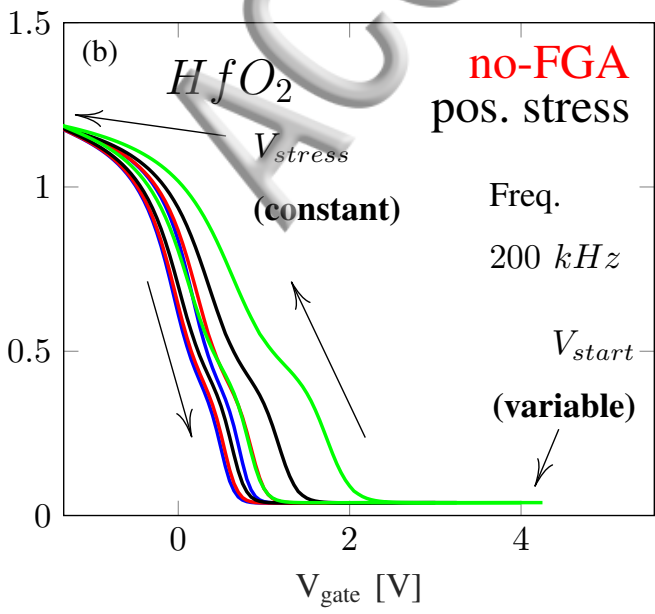




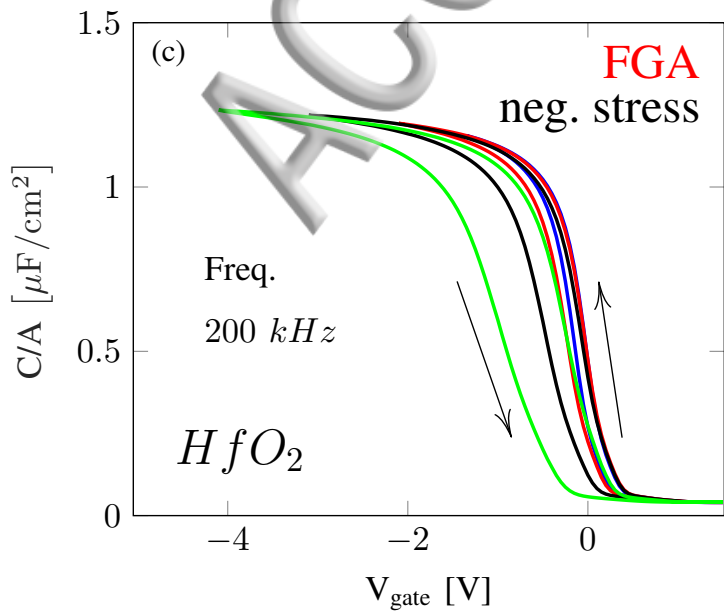




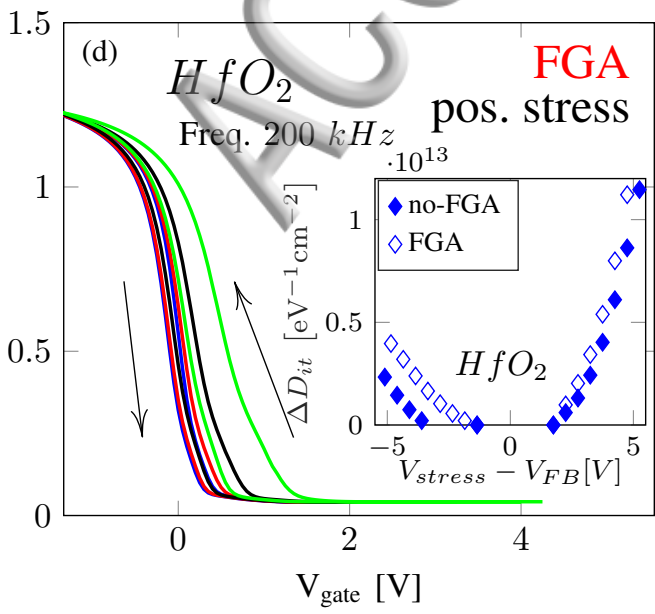




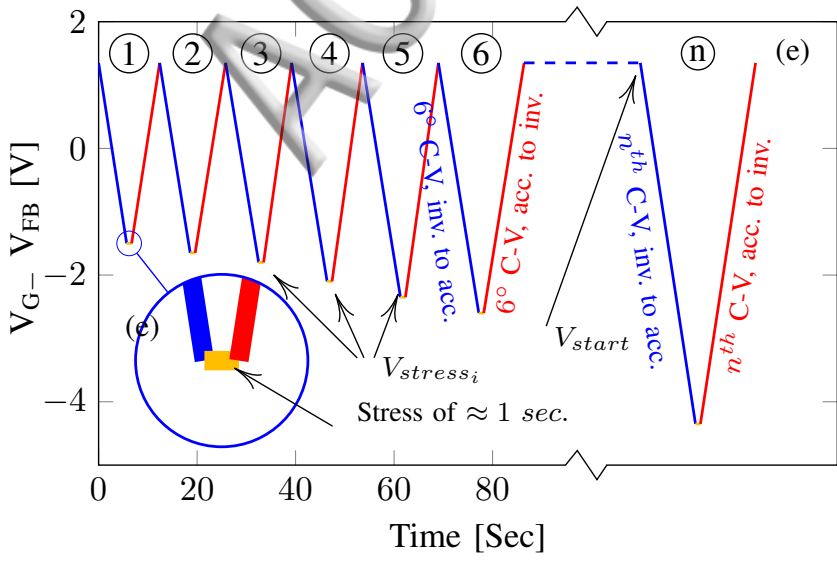




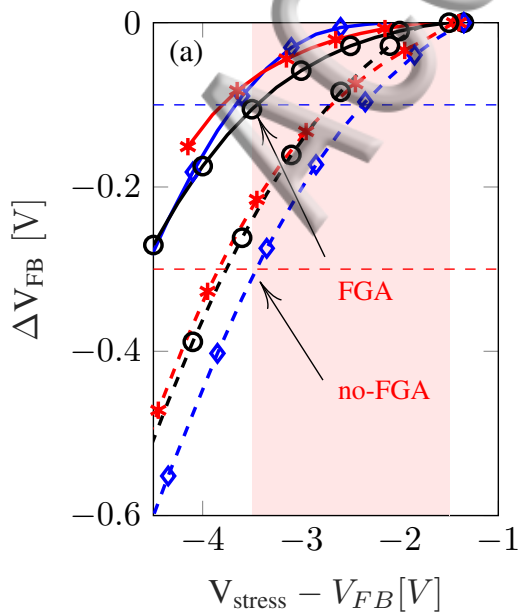




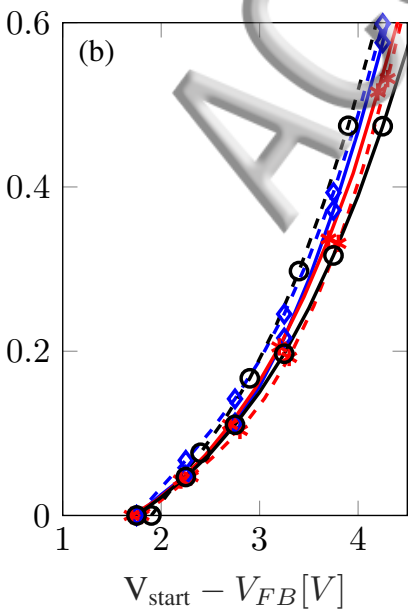




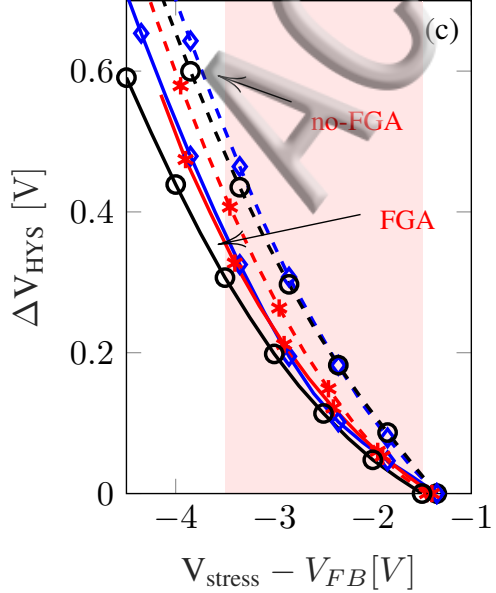




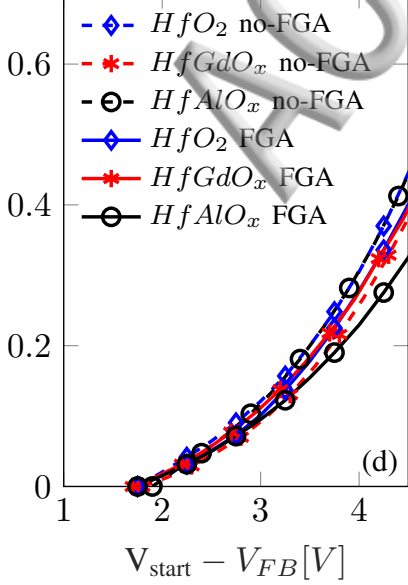




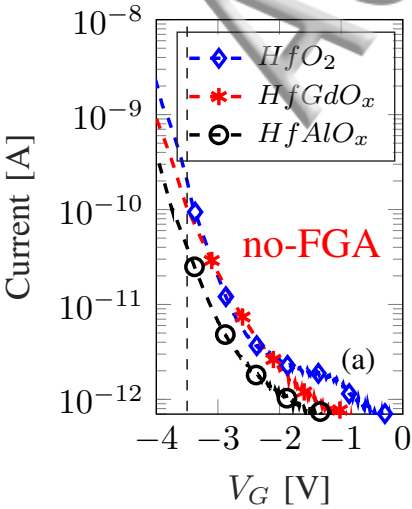




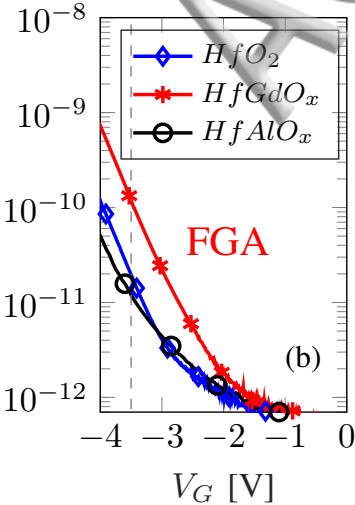




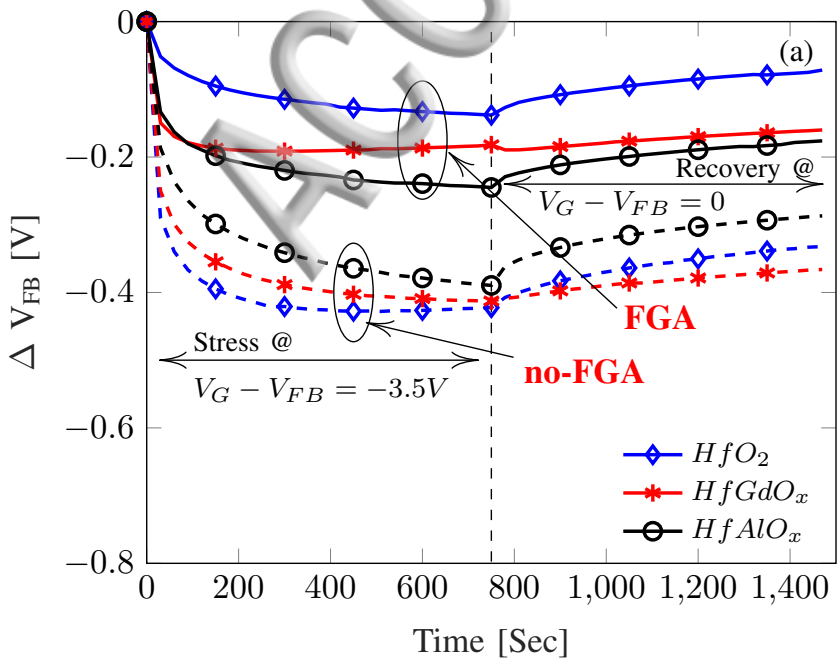


